\title{
A heat-shock inducible system for flexible gene expression in cereals
}

\author{
Sophie A. Harrington' ', Anna E. Backhaus', Samantha Fox', Christian Rogers², Philippa Borrill², \\ Cristobal Uauy ${ }^{*^{*}}$ and Annis Richardson ${ }^{1,4^{*}}$ (D)
}

\begin{abstract}
Background: Functional characterisation of genes using transgenic methods is increasingly common in cereal crops. Yet standard methods of gene over-expression can lead to undesirable developmental phenotypes, or even embryo lethality, due to ectopic gene expression. Inducible expression systems allow the study of such genes by preventing their expression until treatment with the specific inducer. When combined with the Cre-Lox recombination system, inducible promoters can be used to initiate constitutive expression of a gene of interest. Yet while these systems are well established in dicot model plants, like Arabidopsis thaliana, they have not yet been implemented in grasses.

Results: Here we present an irreversible heat-shock inducible system developed using Golden Gate-compatible components which utilises Cre recombinase to drive constitutive gene expression in barley and wheat. We show that a heat shock treatment of $38^{\circ} \mathrm{C}$ is sufficient to activate the construct and drive expression of the gene of interest. Modulating the duration of heat shock controls the density of induced cells. Short durations of heat shock cause activation of the construct in isolated single cells, while longer durations lead to global construct activation. The system can be successfully activated in multiple tissues and at multiple developmental stages and shows no activation at standard growth temperatures $\left(\sim 20^{\circ} \mathrm{C}\right)$.

Conclusions: This system provides an adaptable framework for use in gene functional characterisation in cereal crops. The developed vectors can be easily adapted for specific genes of interest within the Golden Gate cloning system. By using an environmental signal to induce activation of the construct, the system avoids pitfalls associated with consistent and complete application of chemical inducers. As with any inducible system, care must be taken to ensure that the expected construct activation has indeed taken place.
\end{abstract}

Keywords: Inducible promoters, Cre recombinase, Transgenic, Inducible expression, Clonal sectors, Wheat, Barley, Grasses

\section{Background}

Historically, transformation in cereal crops such as wheat and barley has been hampered by low efficiencies and high costs [1]. Yet recent advances in transformation techniques have shown remarkable improvements of transformation efficiency [1,2]. As a result, functional characterisation of cereal genes increasingly uses

\footnotetext{
*Correspondence: Cristobal.Uauy@jic.ac.uk; Annis.Richardson@ed.ac.uk

1 John Innes Centre, Norwich Research Park, Norwich NR4 7UH, UK

Full list of author information is available at the end of the article
}

transgenic approaches. Commonly, genes are characterised using standard over-expression systems, where the gene of interest is placed under the control of a constitutive promoter [3]. In some cases, however, ectopic over-expression can be deleterious or even embryo lethal [4]. This concern has hindered work on certain genes, especially in crops such as wheat and barley given the relatively high cost for transformations which made researchers averse to test over-expression of genes which may lead to embryo lethality. An example of this is a previously identified NAC transcription factor, $N A M-B 1$, 
which is a positive regulator of senescence [5]. Its role in promoting the onset of developmental senescence led to concerns that overexpression of NAM-B1 could lead to premature senescence at the embryo or seedling stage.

A common approach to overcome such difficulties involves the use of an inducible system, whereby the gene of interest is placed under the control of an inducible promoter. The gene is thus only expressed upon application of the required inducer. These systems are useful when dealing with genes whose overexpression may be deleterious for the plant as well as to induce gene expression in specific tissues or at specific developmental times [6]. Chemicals such as $\beta$-estradiol $[7,8]$, ethanol $[6,9]$, and glucocorticoids such as dexamethasone $[10,11]$ have been used successfully to drive inducible transgenic systems in plants. Environmentally-driven systems have also been established, utilising promoters which are induced under specific abiotic stresses, such as heat $[12,13]$, cold [14], or drought [15].

While most of these inducible systems have been implemented in Arabidopsis, within the cereals environmentally-induced promoters have been most well characterised. A barley heat shock promoter, HvHSP17, was used to successfully drive the heat-shock induced expression of the reporter gene GUS in wheat [13]. The promoters of two cold-responsive genes, OsWRKY71 and TdCor39, were used to drive cold-induced expression of the wheat DREB3 gene in both barley and rice [14]. Temperature-independent systems have also been established successfully, including the use of the barley drought-responsive promoter HvDhn4s [15]. Recently, a dexamethasone-inducible system was established in rice, though application of dexamethasone was found to also cause non-specific activation of endogenous rice genes [16].

Yet while these inducible systems have been successful in causing activation of a given gene of interest following application of the required stimulus, they are unable to cause constitutive, non-reversible activation of that gene. These are inherently transitory systems. As a result, these systems must be combined with additional components to allow for constitutive, inducible expression of a gene of interest. One of the most well characterised systems that allows for constitutive activation of a gene of interest is the Cre-Lox system. Initially developed for use in mice [17], but now regularly used in many species including plants $[18,19]$, Cre recombinase is an enzyme derived from the bacteriophage P1 which carries out directional recombination of DNA between two specific DNA sequences, named the loxP sites. This system can therefore be used to excise a desired segment of DNA and has been used in conjunction with inducible systems in model plants to drive the controlled, constitutive activation of gene expression following induction [20, 21]. The benefits of the Cre-Lox system have been amply demonstrated in model species such as Arabidopsis [2224] but have rarely been applied to cereal crops [20]. We therefore aimed to develop a framework for a transgenic system in cereals that would allow the irreversible induction of a gene of interest at the desired developmental stages. In the case of genes like $N A M-B 1$, this allows us to prevent undesired expression of the gene early on in development and thus avoid potential embryo lethality.

Here we have integrated a barley heat-shock specific promoter, HvHSP17, with the Cre-Lox system and shown that we can successfully activate the construct following heat shock treatment and see no expression of the target gene prior to heat shock. Gene activation can be achieved in multiple tissues and distinct developmental stages, demonstrating that the system is versatile. Variable lengths of applied heat shock can control the density of activated cells, with short periods inducing single-cell construct activation and longer periods inducing global activation. Construct activation can be optimised for specific experimental setups to ensure that the desired level of activation occurs.

\section{Results \\ Design of the construct}

To develop a system that would allow for the irreversible induction of a given gene of interest at a specific time, we developed a Cre-Lox system under the control of an inducible promoter. Our aim was to have a construct that consisted of an inducible promoter that would drive expression of Cre recombinase upon application of the appropriate stimulus. Initially, and in the absence of the stimulus, only the reporter gene would be expressed under the control of a constitutive promoter (Fig. 1a). Expression of Cre recombinase after the appropriate treatment (Fig. 1b) then leads to the irreversible excision of the reporter gene, located on the same construct and flanked by two loxP sites (Fig. 1c). Removal of the reporter gene then brings the gene of interest in proximity to a constitutive promoter that drives its expression in an irreversible manner (Fig. 1d). Previously, the barley heat shock promoter $H v H S P 17$ has been shown to be induced upon treatment for $2 \mathrm{~h}$ at $38{ }^{\circ} \mathrm{C}$ in wheat, with minimal background expression at lower temperatures [13]. We therefore selected this promoter as a strong, consistent inducible promoter that could be used to drive expression of the Cre recombinase. We then developed two parallel versions of this construct, one for use in barley for microscopy experiments (Fig. 1e), and one for use in wheat to test the impact of premature $N A M-B 1$ expression on wheat development (Fig. 1f). 


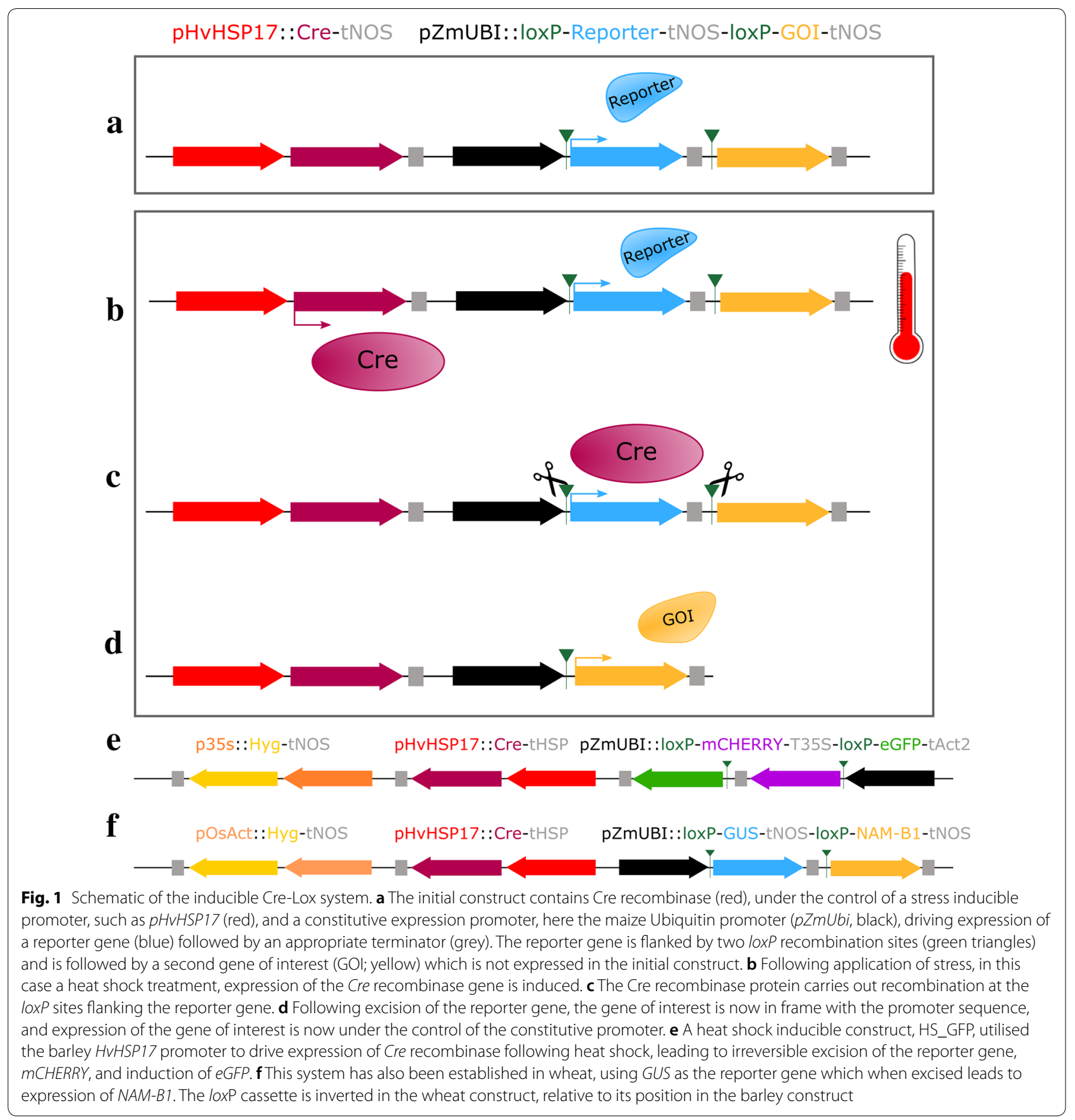

To track the activation of the construct at the cellular level, we required the use of fluorescent reporter proteins that could be effectively visualised using confocal microscopy without being obscured by the autofluorescence in mature barley tissues. To select the best fluorescent proteins for use in barley, we carried out a spectral scan on barley leaf and floral tissue to check for endogenous auto-florescence, which would interfere with fluorescent protein signals. Barley leaf and inflorescence tissue at different developmental stages was harvested and imaged using confocal laser microscopy to assess native fluorescence when excited with different wavelengths appropriate to CyPET [25], eGFP [26], and mCHERRY [27]. For all three wavelengths, auto-fluorescence was only observed at high gain levels, except in the mature leaf tissue which had higher auto-fluorescence (Additional file 2: Figure S1). This suggested that CyPET, eGFP and mCHERRY were suitable to use in barley transgenics, especially 
when observing young tissues. However, the higher level of endogenous auto-fluorescence will need to be considered when imaging mature leaf tissue.

From these reporters, we selected $m C H E R R Y$ for use as the reporter gene, flanked by the loxP sites, and $e G F P$ for use as the induced gene, located downstream of $m C H E R R Y$. These genes were placed under the control of the constitutive maize Ubiquitin promoter, $p Z m U b i$. In both cases, ER-targeting sequences were cloned at the $\mathrm{N}$ - and $\mathrm{C}$-terminals of the fluorescent reporter genes to limit cell-cell movement of the fluorescent proteins. This construct was then cloned in tandem with the Cre gene containing the $U 5$ intron, driven by $p H v H S P 17$, and a selection cassette consisting of Hygromycin under the control of the constitutive $35 S$ promoter (Fig. 1e). Specific details of the sequences and constructs used in the cloning of the barley construct are presented in "Materials and methods" section, and in Additional file 2: Figure S3.

Alongside the barley construct, we developed a secondary version of the construct for transformation into wheat, which utilised a different reporter/gene system. As GUS had been successfully used as a reporter in previous tests of the heat shock promoter [13], we combined the GUS gene, flanked by the loxP sites, with the wheat NAC transcription factor NAM-B1 [5]. The remainder of the construct follows that of the barley construct (Fig. 1f). Details of the specific components used to clone the wheat construct are presented in "Materials and methods" section and Additional file 2: Figure S2.

\section{Characterisation of the heat shock construct Transformation and copy number validation}

$\mathrm{T}_{0}$ transformants of the wheat and barley constructs were obtained in the Fielder and Golden Promise cultivars, respectively, and screened for copy number. We identified 17 independent events which contained the wheat construct, HS_NAM-B1, and eight independent events which contained the barley construct, HS_GFP (Additional file 2: Table S1). Fourteen independent wheat lines and four barley lines were taken forward for copy number analysis. From these lines, four wheat lines with varied copy number were taken forward for the majority of further analysis at the $\mathrm{T}_{1}$ generation. Two single-copy barley lines were taken forward for analysis, one segregating population (00899-01-01) and one homozygous line containing a single insertion, and thus two copies, at the $\mathrm{T}_{1}$ generation (00899-04-01).

\section{Heat shock induces activation of the Cre-Lox construct}

To characterise the heat shock-inducible construct, we first tested whether the application of heat shock to positive transformants would be sufficient to induce expression of Cre recombinase. Based on previous work with the HvHSP17 promoter [13], we expected that $2 \mathrm{~h}$ at $38{ }^{\circ} \mathrm{C}$ would be able to induce expression of Cre. Using $\mathrm{T}_{1}$ plants descended from the wheat 4-copy line 2020-2-1, we found that within $2 \mathrm{~h}$ of heat shock treatment to seedlings, Cre expression could already be detected (Additional file 2: Figure S4).

We investigated whether the expression of Cre was sufficient to cause successful excision of the reporter gene. In wheat seedlings before heat shock treatment, PCR of extracted genomic DNA using primers flanking the loxP sites (Fig. 2a) amplified the expected 2490 bp region encompassing the reporter gene (Fig. 2b). Following $2 \mathrm{~h}$ of heat shock at $38^{\circ} \mathrm{C}$, a shorter band of 151 bp was observed (Fig. 2a, b). This indicated that the Cre recombinase can excise the reporter gene between the two loxP sites. Of the 14 independent wheat lines tested with this assay, all those which expressed the GUS reporter gene also demonstrated successful construct excision following seedling heat shock.

\section{Heat shock leads to the expression of the gene of interest}

As heat shock treatment leads to the successful excision of the reporter gene, we next investigated the expression levels of the gene of interest following recombination. We selected three independent transgenic lines containing the $N A M-B 1$ construct for further testing: 2020-20-02 (one copy), 2020-2-1 (four copies), and 20205-1 (ten copies). We also included the null copy control, 2010-54-01. Three or four individual $T_{1}$ plants of each line were treated at the two-leaf stage either with $2 \mathrm{~h}$ at $38^{\circ} \mathrm{C}$ (heat shock; "HS") or $2 \mathrm{~h}$ at $20^{\circ} \mathrm{C}$ (non-heat shock; "NHS"), and were sampled for RNA extraction 2 weeks after the treatment. qRT-PCR carried out on the samples found that there was no significant expression of NAM$B 1$ in the null copy control under any condition (Fig. 3a), as expected. While there was a statistically significant increase in expression in one of the positive transgenic lines before heat shock ("Pre") compared to the 0 copy control (4 copy line; Student's T-test, $\mathrm{p}<0.05$ ), the spread of gene expression observed was within the biological background levels observed in the 0 copy line. This suggests that no substantial gene expression is observed before heat shock application. However, after heat shock ("Post") all three lines showed a significant (2020-2$1,2020-5-1, \mathrm{p}<0.05)$ or near-significant (2020-20-02, $\mathrm{p} \sim 0.09)$ increase in NAM-B1 above the baseline expression before treatment.

We then tested whether the heat shock treatment was able to induce expression of $e G F P$ in the barley transgenics, using progeny of the $\mathrm{T}_{0}$ lines 00899-04-01 and 0089901-01. A heat treatment of $30 \mathrm{~min}$ of $38^{\circ} \mathrm{C}$ induced high levels of eGFP in the leaf tissue of 1-week old seedlings, 


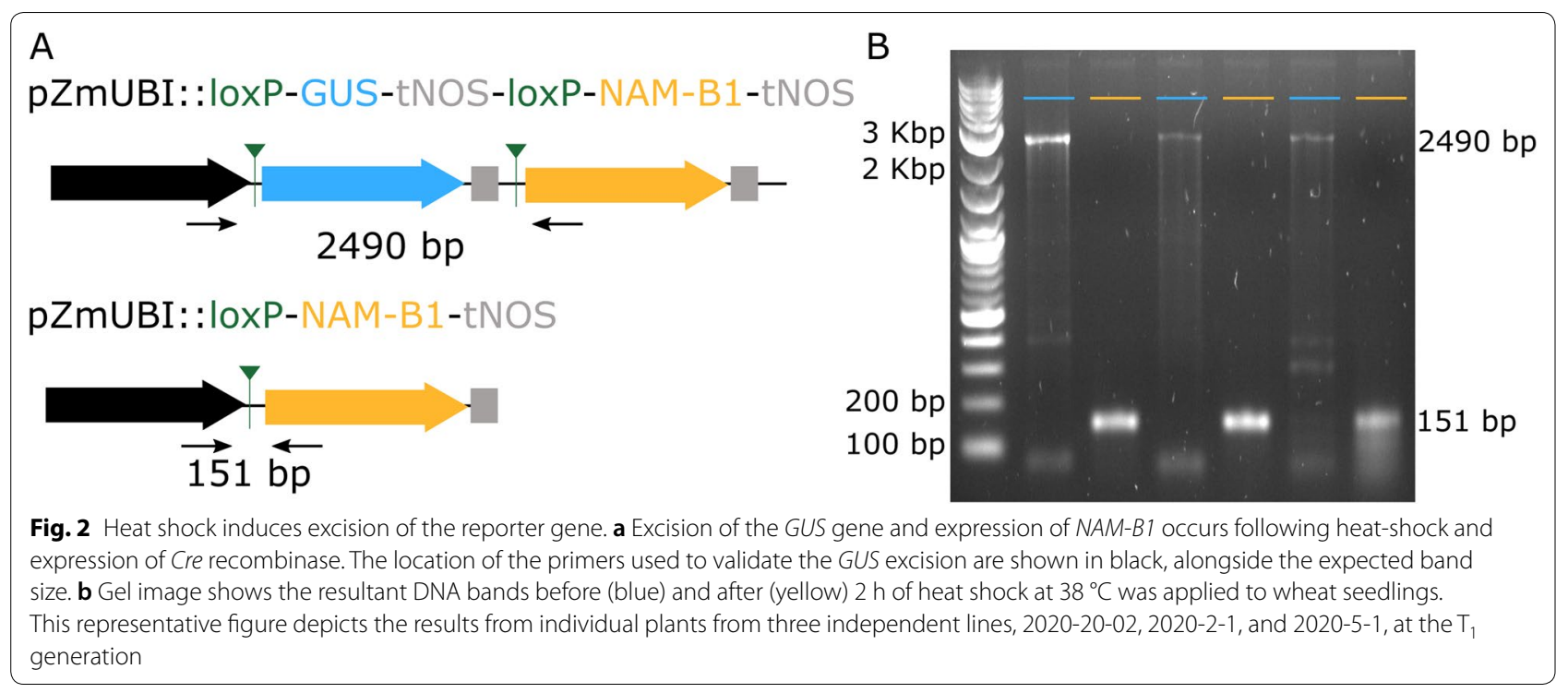

whereas no background expression of eGFP was observed in the untreated controls (Fig. 3b, c; Additional file 2: Fig. S5A-C). Residual expression of mCHERRY is observed in the leaf tissue following heat shock, though this is substantially reduced compared to the untreated control (Fig. 3b, c; Additional file 2: Fig. S5A-C). This will be due in part to the presence of up to two copies of the construct in the lines, as excision of only one copy is required to see eGFP signal. The mCHERRY protein is also known to be highly stable $[27,28]$, and thus some residual protein is likely to remain in the 4 days between construct excision and tissue imaging.

Having shown that the heat shock constructs were functional in both barley and wheat, we then investigated how quickly the induction of the reporter genes can occur following heat shock. Using the single copy wheat line, 2020-20-02, and the homozygous two copy barley line, 00899-04-01, we tested the levels of gene expression at $2,4,12$, and $24 \mathrm{~h}$ following heat shock application. We found that in wheat seedlings, $2 \mathrm{~h}$ after applying a $2-\mathrm{h}$ heat shock treatment at $38^{\circ} \mathrm{C}$ we already saw a significant induction in NAM-B1 expression $(\mathrm{p}<0.05$, Additional file 2: Fig. S6). There was no further increase in gene expression at the later timepoints, indicating that within $2 \mathrm{~h}$ after the completion of the heat shock treatment construct excision had been completed. In barley seedlings the eGFP accumulation at each timepoint following the application of a 30 min heat shock was observed using confocal microscopy (Additional file 2: Fig. S7). We see a gradual increase in eGFP levels from $12 \mathrm{~h}$ post-heat shock, continuing until at least $48 \mathrm{~h}$ after treatment. No further increase in eGFP levels is observed between $48 \mathrm{~h}$ and 8 days after treatment.

\section{Altered durations of heat shock lead to sectorial induction of the gene of interest}

Having demonstrated that application of heat shock is sufficient to induce expression of the gene of interest following excision of the reporter gene, we then investigated whether reducing the duration of heat shock treatment could also cause recombination and gene expression. We visualised the expression of eGFP in 1-week-old barley seedlings from line 00899-04-01 grown on filter paper following the application of a $38^{\circ} \mathrm{C}$ heat shock of varying durations. To assess the effectiveness of the heat shock treatment at penetrating tissue layers, we analysed the eGFP expression in successive leaves. In grasses each leaf primordium (denoted by "P\#", where "P0" describes the primordium most recently initiated at the meristem) encircles the meristem, and any younger leaves that form. Therefore, each leaf primordium forms a new layer through which heat has to penetrate to reach the innermost tissues, such as young leaf primordia and the meristem itself.

No expression of eGFP was observed without heat shock, as expected (Fig. 3d, e). Five minutes of heat shock was sufficient to induce complete eGFP expression in all outer leaves up to the fourth primordium (P4, Fig. 3f). Single cells expressing eGFP were observed in the third primordium (P3) of plants heat-treated for 5 min (Fig. 3g), while no eGFP was observed in the innermost P2 primordium (Fig. 3h). A 15-min heat treatment was sufficient to induce eGFP expression in all leaf layers and tissues, including the second leaf primordium (P2) and the meristem (Fig. 3i), in 1-week-old seedlings. We validated this result in the second barley transgenic line 00899-01-01, confirming that a 15-min heat treatment 

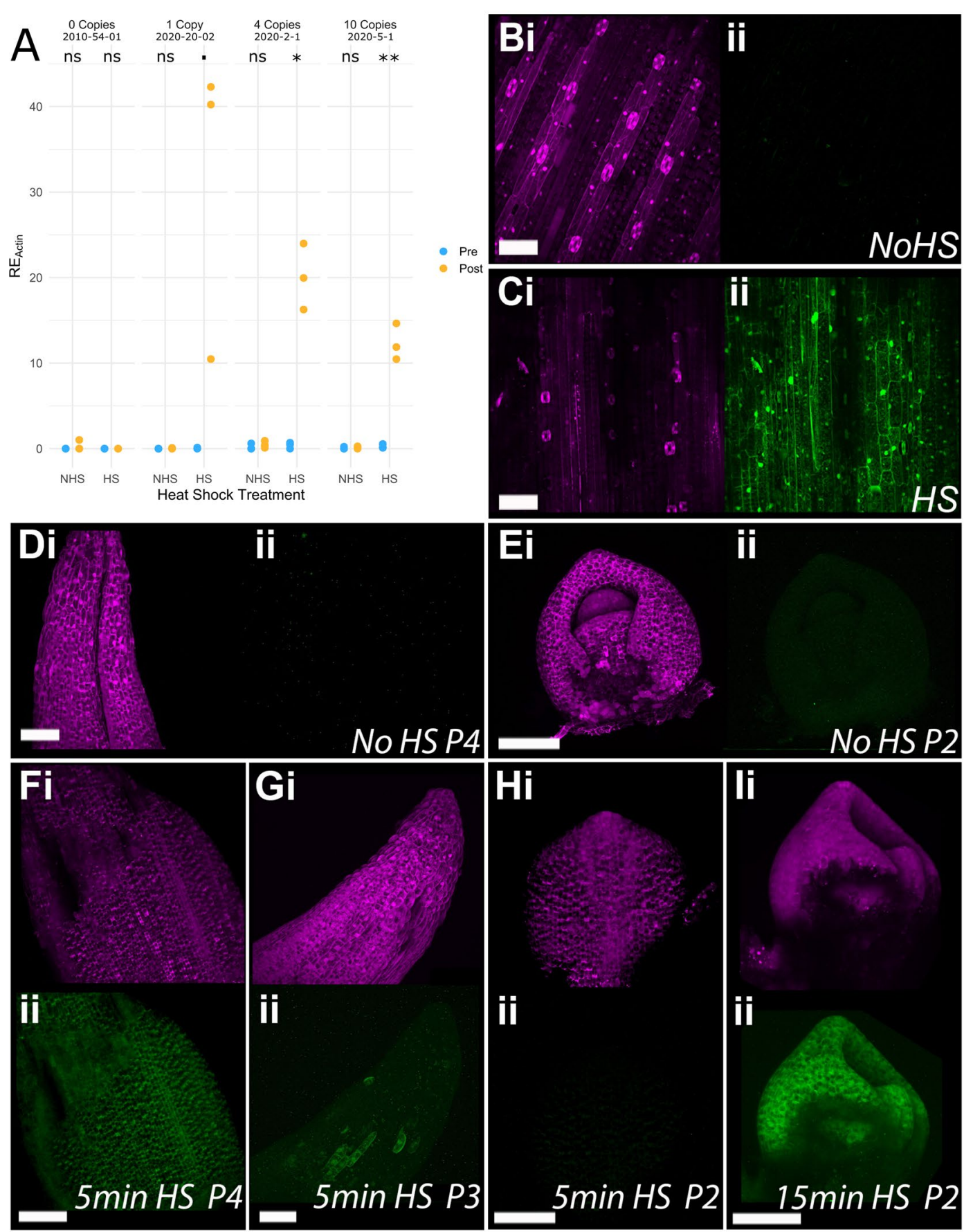

Fig. 3 Heat shock induces gene expression in a duration-dependent manner. a Heat shock (HS) at $38^{\circ} \mathrm{C}$ for $2 \mathrm{~h}$ is sufficient to induce expression of NAM-B1 in wheat at the two-leaf stage, while no significant expression is seen in untreated (NHS) plants. Wheat plants were sampled and RNA extracted 2 weeks after heat shock treatment. b No eGFP expression (ii, green) is observed in leaf tissue of untreated (No HS) 1-week old barley seedlings but is visible in all cells following a 30 min heat shock treatment (c). Both the fourth leaf primordia (d) and the second leaf primordia (e) of barley seedlings show mCHERRY expression (i) but no eGFP expression (ii) before heat shock. After 5 min of heat shock, all cells in the fourth leaf primordia (f) show eGFP while sectorial expression of eGFP is observed in the third leaf primordia (g). No expression of eGFP is observed in the second leaf primordia after 5 min of heat shock (h). However, after 15 min of heat shock, eGFP is expressed in all cells of the meristem and second leaf primordia (i). All barley plants were imaged 3 days after treatment. In each pair of images, the reporter gene mCHERRY is shown in panel $\mathrm{i}$ (magenta), and eGFP is shown in panel ii (green). The reporter gene mCHERRY (magenta) is present in all samples. Scale bars are $100 \mu \mathrm{m}$. The statistical comparison in a was carried out using the Student's T-test, where N is 3 or 4 for each condition; ns, $p>0.1, \cdot p<0.1,{ }^{*} p<0.05,{ }^{* *} p<0.001$. Gene expression in a was determined using qRT-PCR and is reported relative to the housekeeping gene TaActin (RE $\mathrm{Actin})$ 
would be sufficient to induce eGFP expression in both leaf and primordia tissues (Additional file 2: Figure S5D, E). This illustrates the tunability of expression for different tissue layers based on heat shock duration.

\section{Heat shock application at different developmental stages can lead to successful construct activation}

After establishing that the applied heat shock was sufficient to induce gene expression in treated seedlings, we next determined the extent to which this was true at later developmental stages. We found that a 2-h application of heat shock at $38^{\circ} \mathrm{C}$ at the three-leaf stage in soil-grown barley was sufficient to induce gene expression in the outer leaves (i.e. leaf 3, Fig. 4a, b). However, minimal eGFP expression was observed in later developing leaves (i.e. leaf 5, Fig. 4c, d) and no eGFP was observed in the inflorescence meristem (Fig. 4e, f). This suggests that the heat treatment was not able to fully penetrate to the meristematic cells at the three-leaf stage of soil grown plants, resulting in new tissue growth containing only the unexcised construct.

We then investigated whether this result would be recapitulated in the wheat transgenics. Soil-grown plants from lines 2020-20-02, 2020-2-1, and 2020-19-01 ( $\mathrm{n}=5$
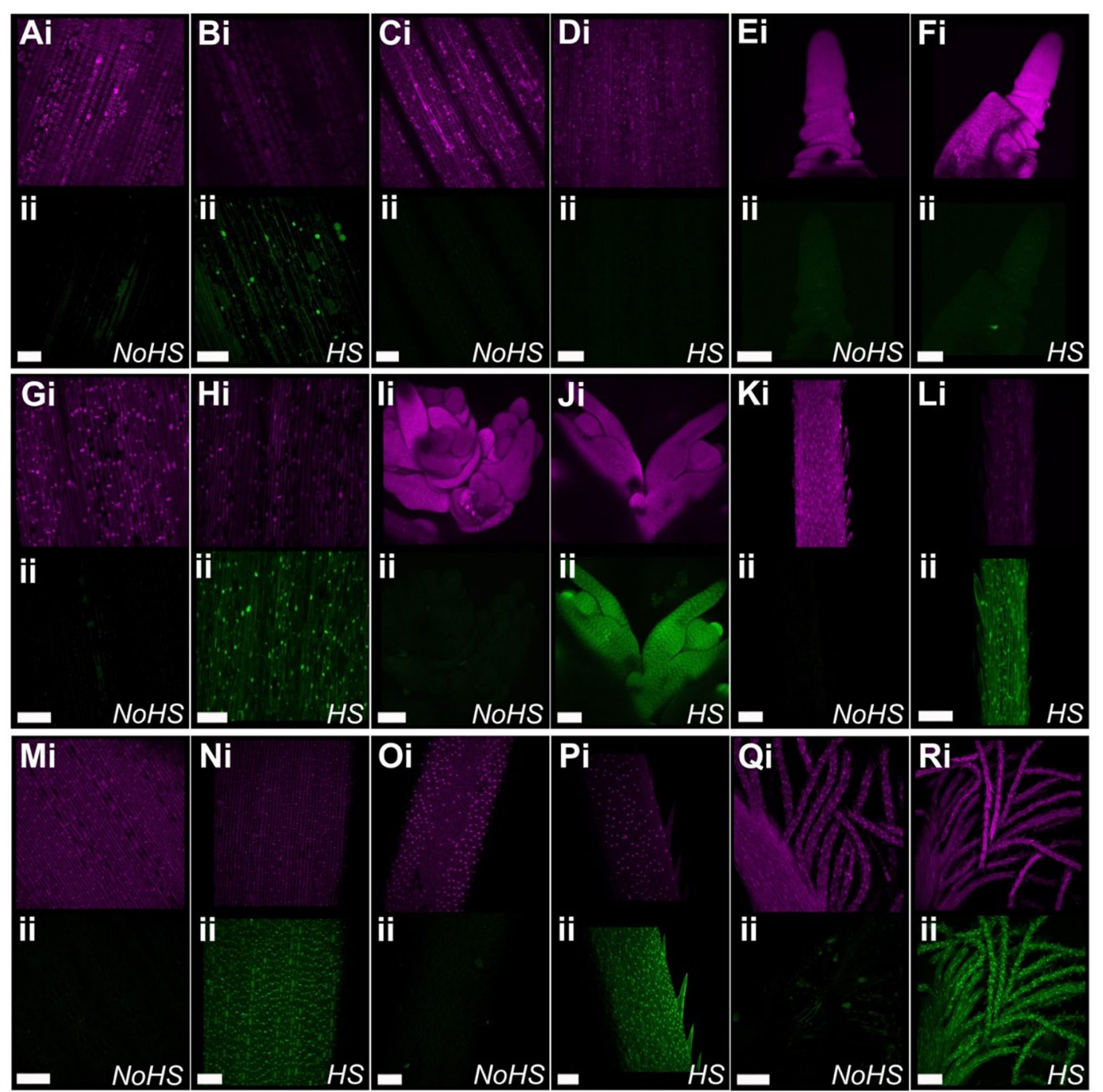

Fig. 4 Testing heat shock stages. Heat shock treatments of plants at different developmental stages: 3 leaf stage (a-f), flag leaf emergence ( $\mathbf{g}-\mathbf{I})$, and ear emergence $(\mathbf{m}-\mathbf{r})$. Heat shock was carried out at $38^{\circ} \mathrm{C}$ for $2 \mathrm{~h}$, and each panel shows the mCHERRY expression (i, magenta) and eGFP expression (ii, green). Tissues are imaged in pairs, showing the equivalent tissue without (left) and with (right) heat shock. a, b Leaf 3, c, d Leaf 5, e, f inflorescence meristem. $\mathbf{g}, \mathbf{h}$ Flag leaf blade, $\mathbf{i}, \mathbf{j}$ developing florets, $\mathbf{k}$, I young awns. $\mathbf{m}, \mathbf{n}$ stem epidermis below the inflorescence, $\mathbf{o}, \mathbf{p}$ mature awn, $\mathbf{q}, \mathbf{r}$ stigma. Scale bars $100 \mu \mathrm{m}$. At all developmental stages, plants were imaged four days after treatment 
for each line) were treated with a $2 \mathrm{~h} 38{ }^{\circ} \mathrm{C}$ heat shock at the three-leaf stage. Similarly to barley, we found that tissue from leaf 3 showed complete excision of the reporter gene (Additional file 2: Figure S8A, "3rd"), while tissue from leaf 5 showed inconsistent excision between independent replicates (Additional file 2: Figure S8A, "5th"). Some individuals (6/15) showed full excision in the leaf 5 tissue (Additional file 2: Figure S8A, left panel), indicating that the meristematic cells from which leaf 5 developed had experienced sufficient heat shock for full excision of the reporter gene. Others showed an intermediate state (4/15), with the presence of both the full construct, at $2490 \mathrm{bp}$, and the excised construct, at $151 \mathrm{bp}$ (Additional file 2: Figure S8A, middle panel). In these cases, it is likely that the fifth leaf developed from a mixture of excised and unexcised primordia cells, leading to a mosaic in the mature tissue. Finally, some individuals showed no evidence of construct excision (5/15), indicating that the fifth leaf primordia cells were not successfully heat shocked (Additional file 2: Figure S8A, right panel).

As a 2-h heat shock treatment at $38{ }^{\circ} \mathrm{C}$ was not sufficient to consistently induce construct excision in the entirety of the three-leaf stage plant, we decided to investigate whether this treatment would be able to induce construct excision at later developmental stages. At the flag leaf emergence stage, we found that this treatment was sufficient to induce complete construct excision in all aerial tissues in barley (Fig. 4g-l). eGFP expression was induced in the flag leaf (Fig. $4 \mathrm{~g}, \mathrm{~h}$ ), the developing florets (Fig. 4i, j), and in the young awns (Fig. 4k, l). This was mirrored in the wheat transgenics, where the same heat shock treatment to lines 2020-2-1 and 2020-19-01 ( $n=6$ for each line) leads to activation of the construct and excision of the reporter gene in both the flag leaf and spikelet tissue (Additional file 2: Figure S8B). In two of the 12 samples, the excision in the basal spikelet was not complete, though the excised construct is also present (Additional file 2: Figure S8B; purple asterisk). We also found that the heat shock treatment of the barley plants at spike emergence was also sufficient to induce $e G F P$ expression in all aerial organs, including in the stem and the floral organs of the plant (Fig. 4m-r).

\section{The heat shock construct is not activated under standard growth conditions}

As treatment at $38{ }^{\circ} \mathrm{C}$ can induce expression of the heatshock driven construct, we then investigated whether temperatures lower than $38{ }^{\circ} \mathrm{C}$ could lead to inadvertent (i.e. "leaky") activation of the construct. We focussed on the barley transgenic system, as the use of fluorescent markers allowed the visualisation of cell-specific changes in expression. In 1-week old seedlings, treated with a heat shock of $30 \mathrm{~min}$, we only observed high levels of eGFP expression at $38^{\circ} \mathrm{C}$ or higher (Fig. $5 \mathrm{~m}-\mathrm{t}$ ). This
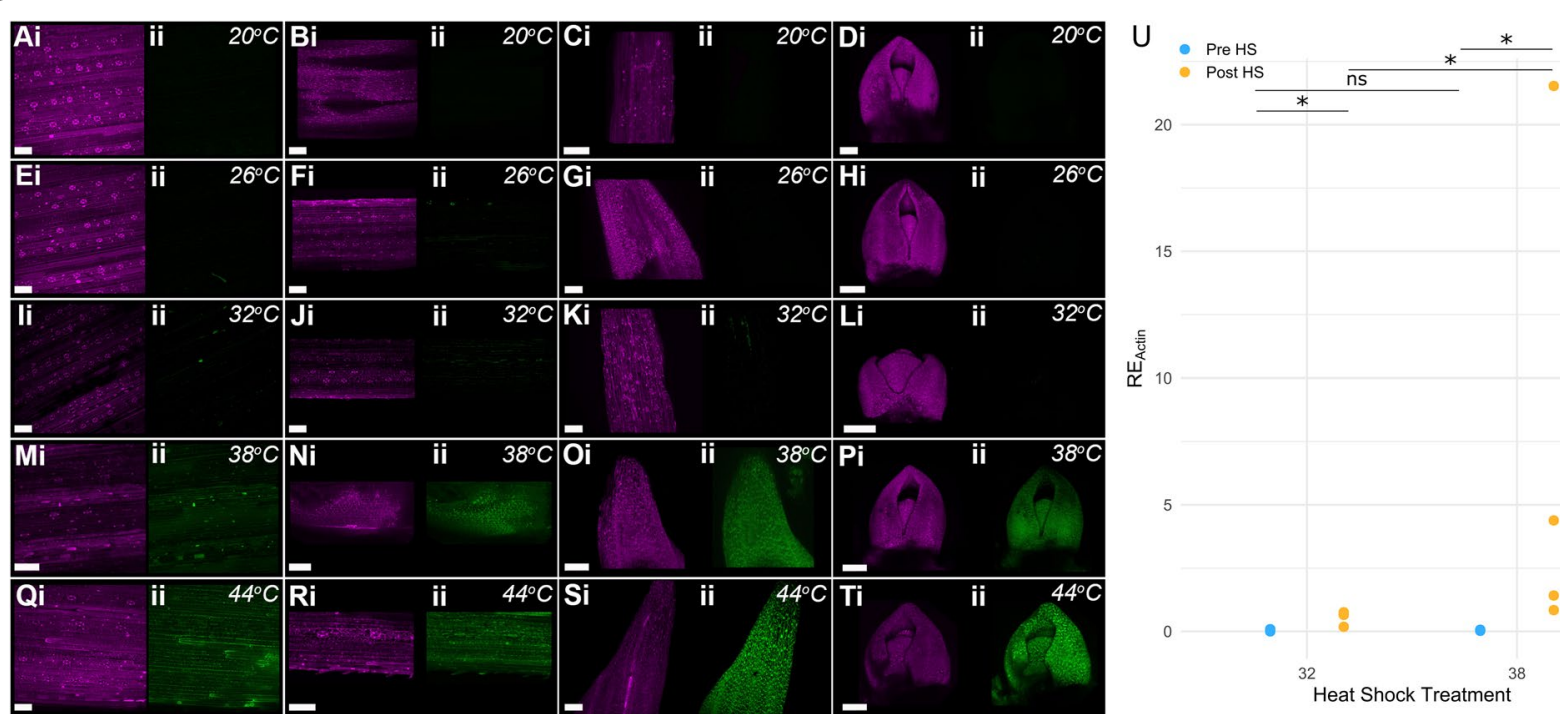

Fig. 5 eGFP is strongly induced only at or above $38^{\circ} \mathrm{C}$. a-t One-week old barley seedings were subjected to a heat shock of 30 min, at one of five different temperatures: $20^{\circ} \mathrm{C}(\mathbf{a}-\mathbf{d}), 26^{\circ} \mathrm{C}(\mathbf{e}-\mathbf{h}), 32^{\circ} \mathrm{C}(\mathbf{i}-\mathbf{l}), 38^{\circ} \mathrm{C}(\mathbf{m}-\mathbf{p})$, and $44{ }^{\circ} \mathrm{C}(\mathbf{q}-\mathbf{t})$. The mCHERRY (i, magenta) and eGFP (ii, green) expression is shown for each tissue sample. Images of leaf $1(\mathbf{a}, \mathbf{e}, \mathbf{i}, \mathbf{m}, \mathbf{q})$, leaf $2(\mathbf{b}, \mathbf{f}, \mathbf{j}, \mathbf{n}, \mathbf{r})$, leaf $3(\mathbf{c}, \mathbf{g}, \mathbf{k}, \mathbf{o}, \mathbf{s})$, and the meristem with attached leaf primordia $(\mathbf{d}, \mathbf{h}, \mathbf{I}, \mathbf{p}, \mathbf{t})$ are shown for each temperature treatment. All plants were imaged 3 days following treatment. The scale bar is $100 \mu \mathrm{m}$. In 1-week old wheat seedlings, NAM-B1 is induced most strongly at $38^{\circ} \mathrm{C}$, though also to a lesser extent at $32^{\circ} \mathrm{C}$ in the single copy line $2020-20-02$ (u). Statistical comparisons were carried out using the Wilcox test due to the non-normality of the data, with $N=4$ for all conditions; ${ }^{*} p<0.05, n s, p>0.05$. Gene expression in $\mathbf{u}$ was determined using qRT-PCR and is reported relative to the housekeeping gene TaActin $\left(\mathrm{RE}_{\mathrm{Actin}}\right)$ 
was consistent across all three emerged leaves and the meristem. At $32{ }^{\circ} \mathrm{C}$, some individual cells exhibited eGFP expression in the emerged leaves (Fig. 5i-k), though no eGFP was observed in the meristem or leaf primordia (Fig. 5l). Even fewer cells expressed eGFP at $26{ }^{\circ} \mathrm{C}$, and only in leaves 1 and 2 (Fig. 5e-h). No expression of eGFP was observed at $20{ }^{\circ} \mathrm{C}$, in keeping with previous experiments (Fig. 5a-d). This was also consistent with previous studies of the HvHSP17 promoter [10].

We then tested whether the induction of the heatshock construct at $32{ }^{\circ} \mathrm{C}$ was visible in the wheat transgenic lines, using 1-week old $\mathrm{T}_{1}$ plants descended from the single-copy line 2020-20-02. Ten days after a 2-h heat shock, qRT-PCR of seedling leaf tissue showed a significant increase in $N A M-B 1$ expression at $38{ }^{\circ} \mathrm{C}$, as expected (Fig. $5 \mathrm{u}, \mathrm{p}<0.05$ ). Those treated with a $2-\mathrm{h}$ $32{ }^{\circ} \mathrm{C}$ heat shock also showed a significant increase in $N A M-B 1$ expression (Fig. $5 \mathrm{u}, \mathrm{p}<0.05$ ). However, the level of expression at $32{ }^{\circ} \mathrm{C}$ was significantly lower than that observed after heat shock at $38^{\circ} \mathrm{C}(\mathrm{p}<0.05)$. This mirrors the comparatively low levels of eGFP expression observed at $32{ }^{\circ} \mathrm{C}$ in the barley transgenics.

\section{Discussion}

In this paper, we demonstrate a system for inducible and irreversible expression of a gene of interest following application of heat shock. This system is functional at different developmental stages and provides the possibility of complete gene induction in the whole plant, or of sectorial gene induction following a shorter application or lower temperature of heat shock. The successful use of the system will require appropriate monitoring of the construct to ensure that both construct excision has occurred when desired, and that premature excision has not occurred.

\section{Use in developmental studies}

The use of an inducible system such as the one presented here will allow more rigorous and detailed developmental studies in cereal crop species. We have demonstrated that by modulating the length of applied heat shock, it is possible to induce variable levels of construct activation through generation of single-cell, sectorial, or wholeplant construct activation. Single-cell activation can be coupled with imaging of developing organs to effectively study the growth and cell division rates within clonal sectors descended from the activated parent cell [29-31]. Similarly, targeted application of heat shock to individual tissues or organs could allow comparison of treated and untreated parts of the plant [32]. For example, a single tiller of a developing wheat plant could be covered and exposed to a heat shock in a water bath, while the remainder of the plant is at room temperature and therefore uninduced. Previous work demonstrated that the activation of the $H v H S P 17$ promoter is highly specific to the treated tissue [13], suggesting that the key limiting factor to this approach would be the ability of the induced protein of interest to travel sym- or apoplastically out of the treated tissue.

This level of specificity compares favourably with that observed in other chemically-inducible systems. Often chemical applications are applied through a foliar spray, in the case of more mature plants, or through growth of seedlings on media containing the chemical inducer [33]. Neither of these methods are conducive for tissuespecific induction of the construct, as is possible with the heat shock-inducible system. In some cases, painting of leaves or other tissues with a solution containing the chemical inducer of interest can lead to spatially-specific induction, however this depends on the mobility of the chemical inducer within the cells. Some chemicals, such as 17-beta-oestradiol are relatively immobile, and thus suitable for this approach, while others, such as dexamethasone, are transported symplastically, making them unsuitable for localised studies [33]. The application method for chemical inducers also raises difficulties when inducing mature plants, or those species which are not amenable to growth on plates. While species such as Arabidopsis thaliana can be grown as seedlings on plates which contain the chemical inducer in the media, ensuring universal uptake and distribution, this is not possible for wheat, barley, and many other larger or less tractable species. So-called "spray and pray" approaches which rely upon ectopic application of the inducer via a foliar spray are notorious for incomplete and inconsistent induction [34]. In contrast, heat shock application relies upon changing the ambient temperature, which inherently affects the entire exposed surface of the plant.

Inducible systems such as these can also be used to study the effect of overexpressing genes which are known or hypothesized to be embryo lethal. This is particularly important in the case of cereal crops and other species where transformation is still non-trivial and often expensive. By using an inducible system, transformed plants can be successfully recovered at the $\mathrm{T}_{0}$ stage without the risk of embryo lethality. After recovering and bulking transformed seeds, the plants can then be heat shocked at the desired developmental stage to induce gene expression. In our case, we initially developed this system in wheat to test the effect of ectopically expressing the wheat senescence regulator $N A M-B 1$ [5]. As a positive regulator of senescence, we hypothesized that this overexpression would be embryo lethal. However, we saw no evidence to suggest that overexpression of $N A M-B 1$ at seedling stage and pre-anthesis affects plant development or causes any symptoms of premature cell death. Further 
work is needed to explore why premature expression of $N A M-B 1$ does not lead to premature senescence or cell death.

This construct can also be adapted for use in more complex systems. For example, the design of the construct could be inverted such that a gene of interest is expressed under the control of the main promoter (in this case $p Z m U b i)$ and is excised from the construct following heat shock. This setup could be used to allow ectopic expression of a gene only until a specific stage of development, at which point it is removed from the construct and no longer expressed. The system could also be coupled to other transgenic systems, for instance an RNAi $[35,36]$ or miRNA construct [37] which either begins silencing of the target gene following heat shock, or conversely only silences the targeted gene until heat shock is applied. The potential applications for this system in cereal crops are substantial and are likely to come into wider use as the efficiency of transformation increases and the costs decrease.

\section{Treatment success depends upon developmental stage}

While the heat shock construct is functional in both barley and wheat, our data demonstrate that not all heat shock conditions are appropriate for activating the construct in all tissues and at all developmental stages. We observed that $5 \mathrm{~min}$ of heat shock was not sufficient to induce activation of the construct in the second leaf primordia (Fig. 3h) and was only able to induce partial activation of the construct in the third leaf primordia (Fig. 3g). However, increasing the length of heat shock application to $15 \mathrm{~min}$ led to complete activation of the construct in the barley meristem and second leaf primordium (Fig. 3i). This discrepancy is likely due to the time it takes for the heat shock to penetrate the inner layers of the plant. Similarly, complete excision of the reporter construct was more difficult to obtain at the three-leaf stage compared to at the seedling stage (Fig. 4). Critically, at this stage the plant is sufficiently juvenile that complete excision in the meristem is essential to ensure that the latterly developed tissue is also expressing the gene of interest. A clear distinction between the assays carried out on the seedlings and those carried out on the older plants is that the seedlings were grown on filter paper, while the older plants were grown in soil. As a result, while the meristem of the seedlings was fully exposed to the heat shock, the meristem of the older plants at three-leaf stage would be located underneath the soil. It is possible that the insulation provided by the soil prevents efficient activation of the construct, compared to that seen in aboveground tissues. Notably, we have not characterised the function of this construct in roots, which are likely to be well insulated to external changes in temperature. For those interested in developing this construct for use in roots, we would encourage bespoke optimisation of the heat shock application method. In general, it is essential that the heat shock is applied in such a manner as to ensure the tissue of interest reaches the desired temperature. Where the tissue is insulated from the heat, either by soil, other tissues, or other means, a longer heat shock may be required to induce the desired level of construct activation.

\section{No construct activation is observed under standard growth conditions}

It is essential that researchers can be sure that the inducible promoter will not be prematurely activated at growth temperatures. To ensure that the construct was sufficiently stable at temperatures below $38^{\circ} \mathrm{C}$, we carried out assays at temperatures ranging from 20 to $38^{\circ} \mathrm{C}$ (Fig. 5). While some construct activation was observed at $26{ }^{\circ} \mathrm{C}$ and $32{ }^{\circ} \mathrm{C}$, this was significantly less than that observed at $38{ }^{\circ} \mathrm{C}$. Critically, no significant activation of the construct was observed at $20^{\circ} \mathrm{C}$, the standard temperature used under light conditions in our controlled growth environments. This indicates that although there is the possibility of unintended construct activation at temperatures below $38{ }^{\circ} \mathrm{C}$, this should not occur under normal growth conditions. We would therefore strongly encourage those working with these constructs to grow plants in controlled environment conditions where possible, ensuring that the plants remain at or below $20^{\circ} \mathrm{C}$. Where this is not possible (e.g. due to space or facilities constraints), it is essential that the plants are grown alongside ambient temperature monitors, which are regularly monitored for any increases in temperature. In all cases, plants should be tested at critical experimental junctures for any unintentional activation of the construct, most cost-effectively through PCR-based assays of construct excision (e.g. in Fig. 2). Experiments should be designed with redundancy in the plant materials, to allow for the loss of individual plants if undesirable construct expression is detected. Finally, and perhaps most critically given the irreversible nature of the excision, seed stocks of lines containing the inactivated construct must be stored with the utmost care to ensure that they remain inactivated. Ideally cold storage would be used, but at a minimum, seeds should be stored away from any sources of ambient heat i.e. sunny windows or radiators, which could heat the seeds above $20^{\circ} \mathrm{C}$.

\section{Conclusions}

Here we have described a heat-shock inducible system which drives constitutive gene expression in barley and wheat. This system, using standard Golden Gate constituent parts, can be adapted for use in developmental 
studies of genes which may otherwise be recalcitrant to transformation. It can also be used to study cell-level development and could be adapted for use in many other contexts. We have shown that the system is versatile, stable under standard growth conditions, and functional in multiple wheat and barley tissues and at various developmental stages. As with all systems of this kind, care must be taken to ensure that construct activation only occurs when desired, and that is has occurred to the expected extent. As more cereal research moves towards gene functional characterisation at the molecular and cellular level [1], transgenic approaches such as this will become increasingly relevant.

\section{Materials and methods}

\section{Construct design}

Golden-gate assembly [38, 39] was used to develop all constructs, utilising parts from TSL SynBio (synbio.tsl. ac.uk) and ENSA (ensa.ac.uk) and following the standard Type IIS cloning syntax, where possible [40]. All constructs used in the course of this study are listed in Additional file 2: Table S2.

Novel parts were created using DNA synthesis using domestication to remove any endogenous BsaI, Esp3I, and BpiI sites from published sequences using neutral base pair changes. All domestication changes produced synonymous amino acid changes and were thus not expected to influence protein function. The Cre recombinase gene sequence (Genbank GeneID: 2777477) and loxP sites (5'-GACCTAATAACTTCGTATAGCATACAT TATACGAAGTTATATTAAGGGTTG-3) were taken from the genome sequence of Enterobacteria Phase P1, domesticated where necessary, and synthesized (Invitrogen Gene Systems).The functional NAM-B1 coding sequence (from Triticum turgidum ssp. dicoccoides) was obtained from NCBI (GenBank DQ869673.1) and domesticated to remove the single BbsI site present in exon 3 (Additional file 1). Introns were approximated based on the gene sequence of the functional homoeolog NAM-A1 in the Chinese Spring reference sequence (TGACv1) [41]. The domesticated gene, with introns, was synthesized by Genewiz.

\section{Level 0 construct synthesis}

To prevent expression of the Cre recombinase during cloning in E. coli, we introduced the Arabidopsis thaliana U5 small nuclear ribonucleoprotein component intron (from pICSL80006, TSL SynBio) at 254 bp in the coding sequence, based on published mammalian studies [42]. The Cre recombinase gene was amplified in two sections, using primer sets designed using the general format: NGAAGACNN+BpiI-specific 4 bp overhang $+18-30 \mathrm{bp}$ of the target sequence ([40]; Additional file 2: Table S3), which introduced flanking BpiI sites and allowed ligation into the pICH41308 backbone. Simultaneously, the U5 intron sequence was amplified to allow ligation between the two $\mathrm{Cre}$ recombinase sequence fragments. $2 \mu \mathrm{L}$ of each PCR fragment was included in the ligation reaction, following the protocol described in [38]. The resulting sequence is provided in Additional file 1.

The domesticated $N A M-B 1$ sequence, and the sequence of the $Z m U b i$ promoter, along with its $5^{\prime} \mathrm{UTR}$ (from pICSL12009 [43]) were cloned directly into the universal acceptor pUAP1 [40] to generate level 0 constructs with the desired 4 base pair overhangs, hereafter pNAM-B1 and pZmUbi, respectively (see primers used in Additional file 2: Table S3). The PCR-amplified sequences were ligated into pUAP1 using the BpiI enzyme, following the protocol from [38].

\section{Level 0.5 construct synthesis}

To introduce flanking loxP sites around the reporter gene and corresponding terminator, an additional step was required alongside the standard Golden Gate cloning protocol. The short $B s a \mathrm{I}$ protocol was carried out as described by TSL Synbio, using the loxP level 0.5 construct developed by ENSA (EC10161) (Fig. 6A). For the wheat construct, the GUS coding sequence from TSL Synbio (pICH75111) and the nosT terminator sequence (pICH41421) were cloned into the loxP construct (Additional file 2: Figure S2A). For the barley construct, an ER targeting sequence (EC71090), the mCHERRY coding sequence (EC71091), the HDEL sequence (EC71020), and the $35 \mathrm{~S}$ terminator (EC41414) were cloned into the loxP construct (Additional file 2: Figure S3A). The ER targeting sequence and the HDEL sequence used are provided in Additional file 1. This created a "level 0.5" vector, hereafter referred to as ploxP-GUS or ploxP-mCHERRY, with loxP sites flanking the coding region and terminator. Unlike standard level 0 constructs, the level 0.5 constructs contain flanking Esp3I sites, rather than $B s a \mathrm{I}$ sites. The level 0.5 construct combines positions B1 and B2 of the standard Type IIS cloning syntax, allowing its insertion upstream of standard coding regions, and downstream of standard promoter regions [40].

\section{Level 1 construct synthesis}

For each system, a level 1 construct was synthesized that combined a constitutive promoter, the loxP-flanked reporter gene, and the gene of interest (Fig. 6b). For the wheat construct, the promoter construct (pZmUbi), the loxP construct (ploxP-GUS), the gene of interest (pNAM-B1), and the nosT terminator (pICH41421) were then cloned into the level 1 backbone, position 3 (pICH47751) (Additional file 2: Figure S2B). For the barley construct, the promoter construct (EC71139), 


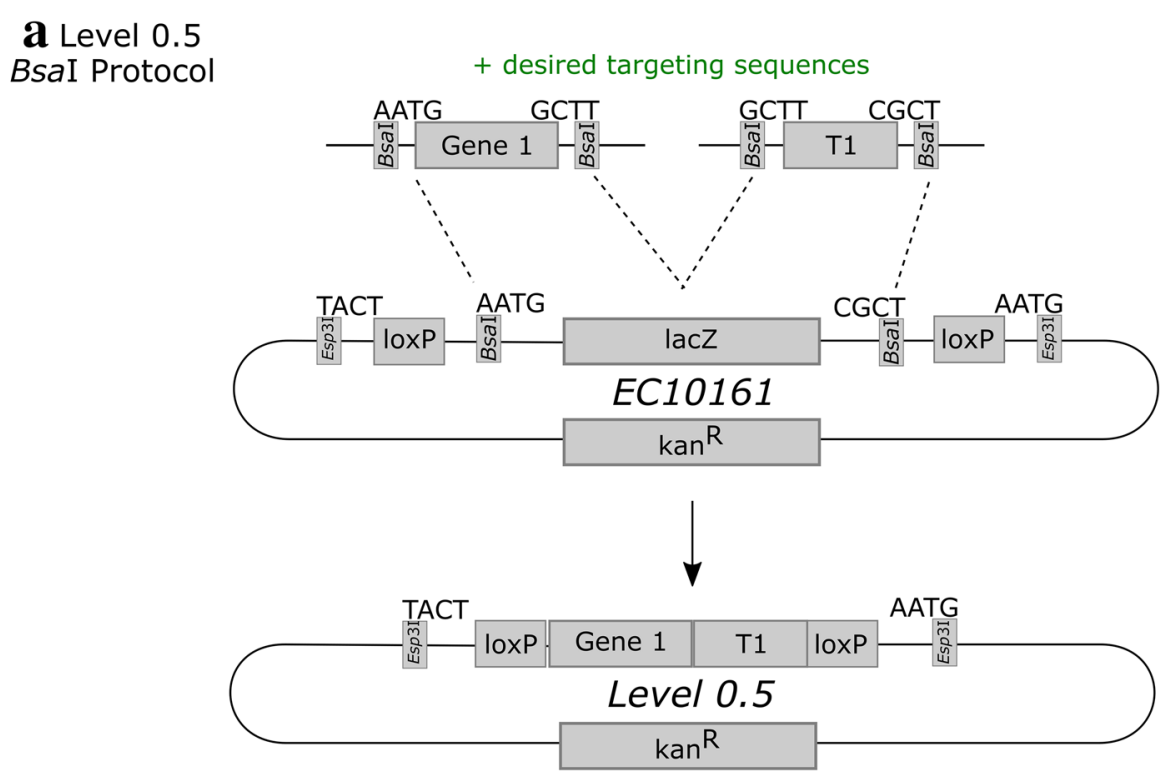

b Level 1

BsaI + Esp3I Protocol
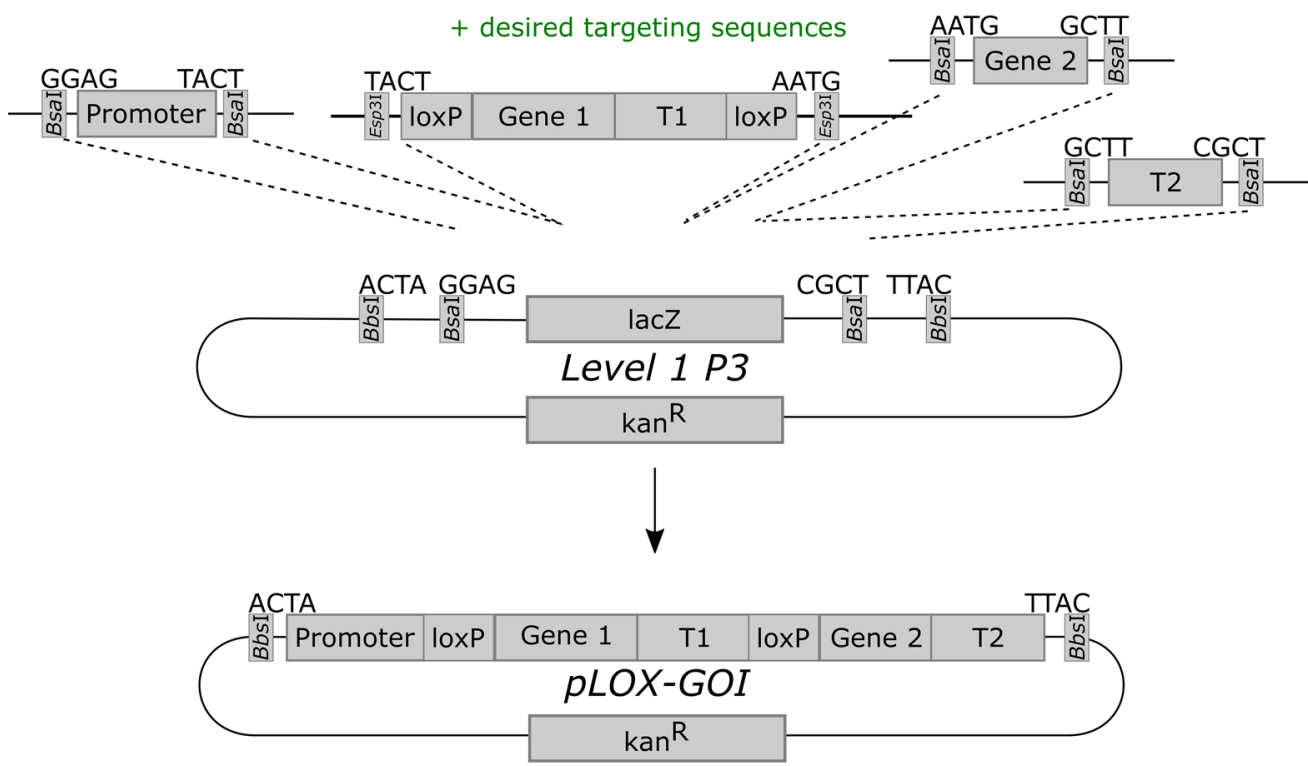

Fig. 6 Assembly of the Level 0.5 and Level 1 vectors. a The reporter gene (Gene 1) and its associated terminator ("T1") were cloned into the Level 0 vector EC10161, using the Type IIS restriction enzyme Bsal. The resulting Level 0.5 vector contains loxP sites flanking the inserted reporter gene and terminator. $\mathbf{b}$ The desired promoter sequence, loxP-flanked reporter gene, gene of interest (Gene 2), and corresponding terminator (T2) are cloned into a Level 1, position 3 vector (e.g. pAGM8031) in a reaction involving both Bsal, for the canonical Level 0 and Level 1 parts, and Esp3l, for the loxP-containing Level 0.5 vector (see a). In both cases, additional components can be included during the cloning step, such as targeting sequences

the loxP construct ( $\mathrm{ploxP}$-mCHERRY), the ER targeting sequence (EC71090), the gene of interest (EC71088), the HDEL sequence (EC71020), and the actin terminator (EC44300) were then cloned into a level 1 backbone, position 3 (EC47822) (Additional file 2: Figure S3B). In both cases, this step used a modified version of the $B s a \mathrm{I}$

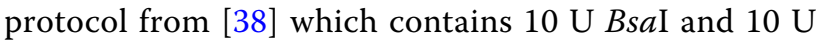
Esp3I, instead of $20 \mathrm{U}$ of BsaI, to allow insertion of the loxP construct (Fig. 1b). 


\section{Level 2/M construct synthesis}

The level 1 constructs were cloned into the appropriate final backbone (level 2/M), integrating the loxP construct with the Cre recombinase construct, and the Hygromycin selection cassette, flanked by right and left border repeats for Agrobacterium-mediated transformation. For the wheat construct, the NAM-B1-loxP level 1 construct was cloned into the level $\mathrm{M}$ backbone (pAGM8031), alongside a selection cassette (pOsAct::Hygromycin, pICH47802), the pHvHsp17::Cre construct (EC71173), and the appropriate end linker (pICH50892, Additional file 2: Figure $\mathrm{S} 2 \mathrm{C})$. For the barley construct, the level 1 eGFP construct, the pHvHSP17::Cre construct (EC71173), and the appropriate end linker (EC41766) were cloned into the level 2 plasmid EC15027, which contains an appropriate Hygromycin expression system (Additional file 2: Figure S3C). Cloning was carried out using the $B b s \mathrm{I}$ protocol from [38]. These constructs will be referred to as HS_NAM-B1 and HS_GFP, respectively. The sequences of all constructs at all stages were verified using Sanger sequencing (Eurofins). The specific cloning steps for the wheat and barley constructs, respectively, are illustrated in Additional file 2: Figures S2 and S3.

\section{Transformation and copy number determination}

The wheat construct was transformed into Triticum aestivum cv. Fielder following previously established protocols as detailed in [3]. The barley construct was transformed into Hordeum vulgare cv. Golden Promise [44]. Agrobacterium-mediated transformation was carried out by the BRACT platform at the John Innes Centre. Positive transformants were identified at the $\mathrm{T}_{0}$ generation by iDNA Genetics (Norwich, UK) using a Taqman probe against the Hygromycin resistance cassette, as described in [3]. This process also assigned copy numbers of the construct to each independent event through the use of qRT-PCR to quantify the presence of the Hygromycin resistance cassette. All wheat experiments were carried out using $\mathrm{T}_{1}$ plants. $\mathrm{T}_{1}$ seedlings were screened for construct presence using a GUS staining as described in [45]. For the barley construct, copy number analysis was also repeated at the $T_{1}$ generation to identify stable homozygous transformants from line 00899-04-01 for use in microscopy.

\section{Wheat growth and phenotyping Seedling heat shock assays}

Seeds were germinated at $4{ }^{\circ} \mathrm{C}$ on damp filter paper for $48 \mathrm{~h}$ in the dark before they were moved to room temperature and were grown under ambient light conditions. The seedlings were grown for 5 to 7 days following germination before the heat shock treatment. Half of the seedlings were treated to a two-hour heat shock at $38{ }^{\circ} \mathrm{C}$ in a temperature-controlled Ecotron incubator (Infors $\mathrm{HT}$ ). The remaining seedlings were left at ambient room temperature during this period.

\section{Controlled environment experiments}

Seeds were germinated at $4{ }^{\circ} \mathrm{C}$ in the dark for $48 \mathrm{~h}$ on damp filter paper, and then allowed to grow for a further $48 \mathrm{~h}$ under ambient light conditions. The germinated seedlings were then sown into P96 trays containing 85\% fine peat with $15 \%$ horticultural grit. They were grown until the 2-3 leaf stage before transplanting into $1 \mathrm{~L}$ pots. The plants experienced cycles of $16 \mathrm{~h}$ of light at $20{ }^{\circ} \mathrm{C}$ and $8 \mathrm{~h}$ of dark at $15{ }^{\circ} \mathrm{C}$ at $60 \%$ relative humidity. Plants received approximately 450-550 $\mu$ mols of photons at flowering height.

Where required, a heat shock treatment was applied to plants grown in soil. Depending on the developmental stage of the plant, either a P96 tray (3-leaf stage or earlier) or up to nine $1 \mathrm{~L}$ pots (flag leaf emergence or later) were taken to a controlled environment chamber (Sanyo MLR-351H) and incubated at $38{ }^{\circ} \mathrm{C}$ for $2 \mathrm{~h}$, at $85 \%$ relative humidity and light level of $270 \mu$ mols of photons, before being returned to the original environment. A second set of non-heat shock controls were left in the original environment for the period of the heat shock.

\section{Barley growth and phenotyping Standard growth conditions}

$\mathrm{T}_{0}$ plants were grown in $1 \mathrm{~L}$ pots in John Innes cereal mix in controlled environment rooms (Gallen Kamp) at 75\% humidity, with a day/night cycle of $16 \mathrm{~h}$ light at $15{ }^{\circ} \mathrm{C}$, $8 \mathrm{~h}$ dark at $12{ }^{\circ} \mathrm{C} . \mathrm{T}_{1}-\mathrm{T}_{3}$ generations were grown in $1 \mathrm{~L}$ pots of cereal mix in temperature-controlled greenhouse conditions, at $20^{\circ} \mathrm{C}$ during the day and $15{ }^{\circ} \mathrm{C}$ during the night, and allowed to self to bulk seed.

\section{Heat shock experiments}

1-week-old seedlings Seeds were germinated on filter paper in plates at room temperature and grown for 1 week before treatment. For heat shock treatment, the seedlings were placed into pre-warmed plastic wallets which were sealed before being immersed in a water bath set to the desired temperature for the desired length of time. Following treatment, the seedlings were removed from the wallets and plated on filter paper to grow for 3 days before dissection and imaging. To assess GFP expression post heat shock, 1-week-old seedlings were exposed to heat shock for 30 min using the above method, then left to grow on filter paper. Seedlings were then harvested and dissected for confocal imaging at each timepoint.

Soil-grown plants Seeds were germinated at $4{ }^{\circ} \mathrm{C}$ in the dark for $48 \mathrm{~h}$ on damp filter paper, and then allowed to 
grow for a further $48 \mathrm{~h}$ at room temperature in the dark. The seedlings were then sown in P96 trays containing M3 mix with insecticide, and grown under controlled conditions with $16 \mathrm{~h} \mathrm{light,} \mathrm{at} 20^{\circ} \mathrm{C}$ and $8 \mathrm{~h}$ of dark, at $15{ }^{\circ} \mathrm{C}$. Plants treated at the three-leaf stage were heat shocked in an incubator for $2 \mathrm{~h}$ at $38^{\circ} \mathrm{C}$ while in the P96 trays. Those treated at the flag leaf emergence and ear emergence stages were transplanted to $1 \mathrm{~L}$ pots before receiving heat shock treatment in the incubator, again at $38^{\circ} \mathrm{C}$ for $2 \mathrm{~h}$. In all cases, plants were returned to the controlled environment conditions for 4 days before dissection and imaging.

\section{Construct excision PCR}

To determine whether the application of heat shock was able to induce excision of the loxP-flanked region by the Cre recombinase, we carried out PCR on genomic DNA (gDNA). gDNA was extracted using the standard DNA extraction protocol, as described in [46]. Primers which flanked the loxP sequences were designed [47] which would amplify different sized fragments depending on the reporter gene being excised or not (Fig. 2a, Additional file 2: Table S3). The PCR was carried out under the following conditions: $5 \mathrm{~min}$ at $95^{\circ} \mathrm{C}, 10$ cycles of $30 \mathrm{~s}$ at $95{ }^{\circ} \mathrm{C}, 1 \mathrm{~min}$ starting at $63{ }^{\circ} \mathrm{C}$ and decreasing by $1{ }^{\circ} \mathrm{C}$ per cycle, and $3 \mathrm{~min}$ at $68^{\circ} \mathrm{C}$, a further 35 cycles of $30 \mathrm{~s}$ at $95^{\circ} \mathrm{C}, 1 \mathrm{~min}$ at $53^{\circ} \mathrm{C}$, and $3 \mathrm{~min}$ at $68^{\circ} \mathrm{C}$, followed by a final extension at $68^{\circ} \mathrm{C}$.

\section{qPCR}

\section{RNA extractions}

Leaf tissue was sampled from individual plants and snap frozen in liquid $\mathrm{N}_{2}$. The stage at which the tissue was sampled depended on the experiment in question. Initial validation of construct expression was carried out on seedling leaf samples, taken between 5- and 7-days following germination from the first true leaf of the plant (i.e. second leaf stage). Tissue samples from plants grown on soil in controlled environment conditions were taken at the third leaf stage. In all cases, approximately $3 \mathrm{~cm}$ of tissue were sampled from the tip of the leaf. The snapfrozen tissue was then ground to a fine powder and RNAs were extracted using TRIzol ${ }^{\circledR}$ Reagent (ThermoFisher). cDNA synthesis was carried out using the Invitrogen M-MLV reverse transcriptase, following treatment with RQ1 RNase-Free DNase (Promega).

\section{$R T-P C R$}

Initial validation of $\mathrm{Cre}$ recombinase expression was carried out using RT-PCR on cDNA samples from lines carrying the heat-shock construct (HS_NAM-B1). Touchdown PCR was carried out on the relevant samples using NEB Taq polymerase using the primer pair SH002/ SH053 (Additional file 2: Table S3) under the following conditions: 5 min at $95{ }^{\circ} \mathrm{C}, 10$ cycles of $30 \mathrm{~s}$ at $95{ }^{\circ} \mathrm{C}$, 1 min starting at $62^{\circ} \mathrm{C}$ and decreasing by $1^{\circ}$ per cycle, and $1 \mathrm{~min}$ at $68^{\circ} \mathrm{C}$, a further 25 cycles of $30 \mathrm{~s}$ at $95^{\circ} \mathrm{C}, 1 \mathrm{~min}$ at $52^{\circ} \mathrm{C}$, and $1 \mathrm{~min}$ at $68^{\circ} \mathrm{C}$, followed by a final extension at $68^{\circ} \mathrm{C}$.

\section{qRT-PCR}

The expression of $N A M-B 1$ in the wheat transgenic lines was validated using quantitative RT-PCR. Primers specific to the domesticated version of $N A M-B 1$ present in the construct were designed and used (SH049/ SH051) alongside previously published primers for the internal control gene TaActin ([5]; Additional file 2: Table S3). Efficiencies for the primers were calculated using pooled cDNA from samples which were known to be expressing the transgenic construct (Additional file 2: Table S3). qRT-PCR reactions were performed using the LightCycler ${ }^{\circledR} 480$ SYBR Green I Master Mix with a LightCycler 480 instrument (Roche Applied Science, UK) under the following conditions: $5 \mathrm{~min}$ at $95^{\circ} \mathrm{C}$; 45 cycles of $10 \mathrm{~s}$ at $95^{\circ} \mathrm{C}, 15 \mathrm{~s}$ at $60^{\circ} \mathrm{C}, 30 \mathrm{~s}$ at $72{ }^{\circ} \mathrm{C}$; followed by a dissociation curve from 60 to $95^{\circ} \mathrm{C}$ to determine primer specificity. In all cases, three technical replicates were carried out per sample and the expression of NAM-B1 was recorded relative to TaActin.

\section{Microscopy}

The spectral scan was carried out using an SP5 II Leica confocal laser microscope, with $\mathrm{a} \times 20$ water immersion lens. During imaging the gain was increased until signal could be seen in each of the fluorescent marker channels (CyPET: 449-508 nm, eGFP: 518-565 nm, mCHERRY: 586-644 nm). In all wild-type tissues this was very high, with gains of over 150 required to visualise the autofluorescence.

Imaging of the heat shocked plants was carried out on a Leica SP8 confocal microscope with a $\times 20$ water immersion objective. Laser power was set to $1 \%$ and $\mathrm{HyD}$ detectors were used for both the mCHERRY and eGFP, with gain $<75$ and pinhole set to $1 \mathrm{AU}$. Z-stack images were collected with line sequential scans to minimise crosstalk between the mCHERRY and eGFP emissions. Images were analysed using FIJI [48] and figures were generated using Adobe Photoshop. All images shown in the figures are Z-stack images and are representative images of at least 4 plants for each condition or timepoint.

\section{Statistical analysis and data visualisation}

All statistical tests were carried out in $\mathrm{R}$ ( $\mathrm{v}$ 3.6.3). Where data followed the normal distribution, the Student's T-test was used to compare samples, and where this assumption was not met, the non-parametric 
Wilcoxon Rank-Sum test was applied. The specific test used in each case is noted within the results and the figure captions. Sample size is indicated in figure captions. All graphs were created in R, using ggplot2 [49], and statistical comparisons were added using Inkscape.

\section{Supplementary information}

Supplementary information accompanies this paper at https://doi. org/10.1186/s13007-020-00677-3.

Additional file 1. Contains gene sequences of NAM-B1 and Cre which were domesticated for use in cloning.

Additional file 2. Contains all Additional Figures and Tables referred to in the text.

\section{Acknowledgements}

We gratefully acknowledge the support from BRACT at the JIC for carrying out transformation and selection of the transgenic barley and wheat plants, and the support from the Horticultural Services at the John Innes Centre while growing the transgenic lines. We also acknowledge support provided by the University of Edinburgh Plant Growth facilities, in particular Dr. Sophie Haupt and Patricia Watson. We also acknowledge the resources provided from TSL SynBio and ENSA, particularly for providing easy access to their constructs and support in the design and cloning stages. We also acknowledge Professor Enrico Coen at the John Innes Centre for providing initial financial support when developing the system.

\section{Authors' contributions}

$A R, C U, S A H$, and PB conceived the study. AR, SAH, CR, and SF carried out the construct design and cloning. AR characterised the barley construct. SAH and $A B$ characterised the wheat construct. SAH drafted the manuscript, and SAH, $A R$, and $C U$ edited the manuscript. All authors read and approved the final manuscript.

\section{Funding}

This work was supported by the John Innes Foundation (to $S A H, A R$, and $A B$ ), by grants from the John Innes Centre Institute Strategic Fund (to CU and AR), and the UK Biotechnology and Biological Sciences Research Council (Grants BB/P016855/1 and BB/P013511/1 and fellowship BB/M014045/1 to PB). This work was also supported by the project Engineering the Nitrogen Symbiosis for Africa (ENSA) currently supported through a grant to the University of Cambridge by the Bill \& Melinda Gates Foundation and UK government's Department for International Development (DFID).

\section{Availability of data and materials}

The datasets supporting the conclusions of this article are included within the article and its additional files. All constructs generated in this study will be made available on Addgene (https://www.addgene.org/Cristobal_Uauy/). Constructs used in this study which were developed elsewhere are listed in Additional file 2: Table S2 and can be accessed through contacting the appropriate institution. Note that ENSA has no facility for directly distributing constructs, however ENSA will put interested researchers in contact with those who can distribute the constructs. Germplasm generated in this study is available from the Germplasm Resources Unit (GRU) under store codes DPRM0075-DPRM0079 (www.seedstor.ac.uk).

\section{Ethics approval and consent to participate}

Not applicable.

\section{Consent for publication}

Not applicable.

\section{Competing interests}

The authors declare they have no competing interests.

\section{Author details}

${ }^{1}$ John Innes Centre, Norwich Research Park, Norwich NR4 7UH, UK. ${ }^{2}$ ENSA, Sainsbury Laboratory, University of Cambridge, Cambridge CB2 1LR, UK. ${ }^{3}$ School of Biosciences, University of Birmingham, Birmingham B15 2TT, UK.

${ }^{4}$ Institute of Molecular Plant Sciences, School of Biological Sciences, University of Edinburgh, Edinburgh EH9 3BF, UK.

Received: 2 June 2020 Accepted: 1 October 2020

Published online: 14 October 2020

\section{References}

1. Adamski NM, Borrill P, Brinton J, Harrington SA, Marchal C, Bentley AR, et al. A roadmap for gene functional characterisation in crops with large genomes: Lessons from polyploid wheat. eLife. 2020;9:e55646.

2. Debernardi JM, Tricoli DM, Ercoli MF, Hayta S, Ronald P, Palatnik JF, et al. A chimera including a GROWTH-REGULATING FACTOR (GRF) and its cofactor GRF-INTERACTING FACTOR (GIF) increases transgenic plant regeneration efficiency. bioRxiv. 2020:2020.08.23.263905.

3. Hayta S, Smedley MA, Demir SU, Blundell R, Hinchliffe A, Atkinson N, et al. An efficient and reproducible Agrobacterium-mediated transformation method for hexaploid wheat (Triticum aestivum L.). Plant Methods. 2019;15(1):121.

4. Yang Y, Karlson DT. Overexpression of AtCSP4 affects late stages of embryo development in Arabidopsis. J Exp Bot. 2011;62(6):2079-91.

5. Uauy C, Distelfeld A, Fahima T, Blechl A, Dubcovsky J. A NAC Gene regulating senescence improves grain protein, zinc, and iron content in wheat. Science. 2006:314(5803):1298-301.

6. Caddick MX, Greenland AJ, Jepson I, Krause KP, Qu N, Riddell KV, et al. An ethanol inducible gene switch for plants used to manipulate carbon metabolism. Nat Biotechnol. 1998;16(2):177-80.

7. Bruce W, Folkerts O, Garnaat C, Crasta O, Roth B, Bowen B. Expression profiling of the maize flavonoid pathway genes controlled by estradiolinducible transcription factors CRC and P. Plant Cell. 2000;12(1):65-80.

8. Zuo J, Niu QW, Chua NH. Technical advance: an estrogen receptor-based transactivator XVE mediates highly inducible gene expression in transgenic plants. Plant J. 2000;24(2):265-73.

9. Roslan HA, Salter MG, Wood CD, White MR, Croft KP, Robson F, et al. Characterization of the ethanol-inducible alc gene-expression system in Arabidopsis thaliana. Plant J. 2001;28(2):225-35.

10. Kirch $T$, Simon R, Grunewald M, Werr W. The DORNROSCHEN/ENHANCER OF SHOOT REGENERATION 1 gene of Arabidopsis acts in the control of meristem ccll fate and lateral organ development. Plant Cell. 2003; 15(3):694-705

11. Jasinski S, Piazza P, Craft J, Hay A, Woolley L, Rieu I, et al. KNOX action in Arabidopsis is mediated by coordinate regulation of cytokinin and gibberellin activities. Curr Biol. 2005;15(17):1560-5.

12. Shinmyo A, Shoji T, Bando E, Nagaya S, Nakai Y, Kato K, et al. Metabolic engineering of cultured tobacco cells. Biotechnol Bioeng. 1998;58(2-3):329-32.

13. Freeman J, Sparks CA, West J, Shewry PR, Jones HD. Temporal and spatial control of transgene expression using a heat-inducible promoter in transgenic wheat. Plant Biotechnol J. 2011;9(7):788-96.

14. Kovalchuk N, Jia W, Eini O, Morran S, Pyvovarenko T, Fletcher S, et al. Optimization of TaDREB3 gene expression in transgenic barley using cold-inducible promoters. Plant Biotechnol J. 2013;11(6):659-70.

15. Xue GP, Way HM, Richardson T, Drenth J, Joyce PA, Mclntyre CL. Overexpression of TaNAC69 leads to enhanced transcript levels of stress upregulated genes and dehydration tolerance in bread wheat. Mol Plant. 2011:4(4):697-712.

16. Vlad D, Abu-Jamous B, Wang P, Langdale JA. A modular steroid-inducible gene expression system for use in rice. BMC Plant Biol. 2019;19(1):426

17. Sauer B. Inducible gene targeting in mice using the Cre/lox system. Methods. 1998;14(4):381-92.

18. Dale EC, Ow DW. Intra- and intermolecular site-specific recombination in plant cells mediated by bacteriophage P1 recombinase. Gene. 1990;91(1):79-85

19. Odell J, Caimi P, Sauer B, Russell S. Site-directed recombination in the genome of transgenic tobacco. Mol Gen Genet. 1990;223(3):369-78. 
20. Srivastava V, Anderson OD, Ow DW. Single-copy transgenic wheat generated through the resolution of complex integration patterns. PNAS. 1999:96(20):11117.

21. Joubès J, De Schutter K, Verkest A, Inzé D, De Veylder L. Conditional, recombinase-mediated expression of genes in plant cell cultures. Plant J. 2004;37(6):889-96.

22. Sieburth LE, Drews GN, Meyerowitz EM. Non-autonomy of AGAMOUS function in flower development: use of a Cre/loxP method for mosaic analysis in Arabidopsis. Development. 1998;125(21):4303-12.

23. Gallois J-L, Woodward C, Reddy GV, Sablowski R. Combined SHOOT MERISTEMLESS and WUSCHEL trigger ectopic organogenesis in Arabidopsis. Development. 2002;129(13):3207.

24. Bencivenga S, Serrano-Mislata A, Bush M, Fox S, Sablowski R. Control of oriented tissue growth through repression of organ boundary genes promotes stem morphogenesis. Dev Cell. 2016;39(2):198-208.

25. Nguyen AW, Daugherty PS. Evolutionary optimization of fluorescent proteins for intracellular FRET. Nat Biotechnol. 2005;23(3):355-60.

26. Zhang G, Gurtu V, Kain SR. An enhanced green fluorescent protein allows sensitive detection of gene transfer in mammalian cells. Biochem Biophys Res Commun. 1996;227(3):707-11.

27. Shaner NC, Campbell RE, Steinbach PA, Giepmans BN, Palmer AE, Tsien RY. Improved monomeric red, orange and yellow fluorescent proteins derived from Discosoma sp. red fluorescent protein. Nat Biotechnol. 2004;22(12):1567-72.

28. Hebisch E, Knebel J, Landsberg J, Frey E, Leisner M. High variation of fluorescence protein maturation times in closely related Escherichia coli strains. PLoS ONE. 2013;8(10):e75991-e.

29. Kuchen EE, Fox S, de Reuille PB, Kennaway R, Bensmihen S, Avondo J, et al. Generation of leaf shape through early patterns of growth and tissue polarity. Science. 2012;335(6072):1092-6.

30. Sauret-Güeto S, Schiessl K, Bangham A, Sablowski R, Coen E. JAGGED controls Arabidopsis petal growth and shape by interacting with a divergent polarity field. PLoS Biol. 2013;11(4):e1001550-e.

31. Whitewoods CD, Gonçalves B, Cheng J, Cui M, Kennaway R, Lee K, et al. Evolution of carnivorous traps from planar leaves through simple shifts in gene expression. Science. 2020;367(6473):91.

32. Serrano-Mislata A, Bencivenga S, Bush M, Schiessl K, Boden S, Sablowski R. DELLA genes restrict inflorescence meristem function independently of plant height. Nat Plants. 2017;3(9):749-54.

33. Moore I, Samalova M, Kurup S. Transactivated and chemically inducible gene expression in plants. Plant J. 2006;45(4):651-83.

34. Kuhlemeier C, Green P. Studying plant development: an alternative to "spray and pray". Genes Dev. 1987;1(1):3-5.

35. Gupta S, Schoer RA, Egan JE, Hannon GJ, Mittal V. Inducible, reversible, and stable RNA interference in mammalian cells. PNAS. 2004;101(7):1927.

36. Tiscornia G, Tergaonkar V, Galimi F, Verma IM. CRE recombinase-inducible RNA interference mediated by lentiviral vectors. PNAS. 2004;101(19):7347.
37. Garwick-Coppens SE, Herman A, Harper SQ. Construction of permanently inducible miRNA-based expression vectors using site-specific recombinases. BMC Biotechnol. 2011;11:107.

38. Weber E, Engler C, Gruetzner R, Werner S, Marillonnet S. A modular cloning system for standardized assembly of multigene constructs. PLOS ONE. 2011;6(2):e16765.

39. Werner S, Engler C, Weber E, Gruetzner R, Marillonnet S. Fast track assembly of multigene constructs using Golden Gate cloning and the MoClo system. Bioengineered. 2012;3(1):38-433.

40. Patron NJ, Orzaez D, Marillonnet S, Warzecha H, Matthewman C, Youles $M$, et al. Standards for plant synthetic biology: a common syntax for exchange of DNA parts. New Phytol. 2015;208(1):13-9.

41. Clavijo BJ, Venturini L, Schudoma C, Accinelli GG, Kaithakottil G, Wright J, et al. An improved assembly and annotation of the allohexaploid wheat genome identifies complete families of agronomic genes and provides genomic evidence for chromosomal translocations. Genome Res. 2017;27(5):885-96.

42. Kaczmarczyk SJ, Green JE. A single vector containing modified cre recombinase and LOX recombination sequences for inducible tissue-specific amplification of gene expression. Nucleic Acids Res. 2001;29(12):e56-e.

43. Lawrenson T, Shorinola O, Stacey N, Li C, Østergaard L, Patron N, et al. Induction of targeted, heritable mutations in barley and Brassicaoleracea using RNA-guided Cas9 nuclease. Genome Biol. 2015;16(1):258.

44. Harwood WA. A protocol for high-throughput Agrobacterium-mediated barley transformation. Methods Mol Biol. 2014;1099:251-60.

45. Jefferson RA, Kavanagh TA, Bevan MW. GUS fusions: beta-glucuronidase as a sensitive and versatile gene fusion marker in higher plants. EMBO J. 1987;6(13):3901-7.

46. Pallotta MA, Warner P, Fox RL, Kuchel H, Jefferies SJ, Langridge P, editors. Marker assisted wheat breeding in the southern region of Australia. In: 10th international wheat genetics symposium. Paestum, Italy: Instituto Sperimentale per la Cerealicolutra. 2003.

47. Borrill PGM. The NAM-B1 transcription factor and the control of grain composition in wheat. University of East Anglia; 2013.

48. Schindelin J, Arganda-Carreras I, Frise E, Kaynig V, Longair M, Pietzsch T, et al. Fiji: an open-source platform for biological-image analysis. Nat Methods. 2012;9(7):676-82.

49. Wickham H. ggplot2: elegant graphics for data analysis. New York: Springer; 2016.

\section{Publisher's Note}

Springer Nature remains neutral with regard to jurisdictional claims in published maps and institutional affiliations.

Ready to submit your research? Choose BMC and benefit from:

- fast, convenient online submission

- thorough peer review by experienced researchers in your field

- rapid publication on acceptance

- support for research data, including large and complex data types

- gold Open Access which fosters wider collaboration and increased citations

- maximum visibility for your research: over 100M website views per year

At BMC, research is always in progress.

Learn more biomedcentral.com/submissions 